JPPKMI 1 (1) (2020)
JURNAL PENELITIAN DAN PENGEMBANGAN
KESEHATAN MASYARAKAT INDONESIA
Jttps://journal.unnes.ac.id/sju/index.php/jppkmi

\title{
Shift Kerja dan Masa Kerja Terhadap Kelelahan Kerja pada Pengemudi Angkutan Batu Bara
}

\author{
H. Akhmad Maulani ${ }^{1} \bowtie$, Sukismanto $^{1}$, Hesti Yuningrum ${ }^{1}$, Ariyanto Nugroho ${ }^{1}$ \\ ${ }^{1}$ Program Studi Kesehatan Masyarakat, Universitas Respati Yogyakarta, Indonesia
}

\begin{abstract}
Abstrak
Pendahuluan: Kelelahan kerja yang tinggi merupakan faktor resiko terjadinya kecelakaan kerja. Faktor kelelahan kerja karena jam kerja dan masa kerja yang lama, sehingga tujuan penelitian untuk mengetahui hubungan antara shift kerja dan masa kerja dengan kelelahan kerja pada pengemudi angkutan batu bara. Metode: Metode Penelitian kuantitatif dengan pendekatan cross sectional. Sampel diambil dengan simple random sampling pada pengemudi angkutan batu bara di PT. Bukit Makmur Kalimantan Selatan yang berjumlah 71 orang dan dianalisis dengan menggunakan uji Mann- Whitney tingkat kepercayaan 95\%. Hasil: Hasil menunjukkan responden yang bekerja pada shift malam dan mengalami kelelahan sedang berjumlah 18 orang (25.4\%). Berdasarkan analisis bivariat diperoleh nilai $\mathrm{p}=0.022(\mathrm{p}<0.05)$. Responden yang mempunyai masa kerja lama dan mengalami kelelahan sedang berjumlah 22 orang $(31.0 \%)$. Berdasarkan analisis bivariat diperoleh nilai $\mathrm{p}=0.000(\mathrm{p}<0.05)$. Penutup: Kesimpulan bahwa shift kerja dan masa kerja merupakan faktor yang berhubungan dengan kelelahan kerja pada pengemudi angkutan batu bara di PT. Bukit Makmur Kalimantan Selatan.
\end{abstract}

Alamat korespondensi:

Jln Raya Tajem 1,5 Maguwoharjo

Depok Sleman D.I. Yogyakarta

E-mail: h.akhmad maulani@vahoo.com 


\section{PENDAHULUAN}

Keselamatan dan kesehatan kerja pekerja adalah amanah Undang-undang Nomor 1 tahun 1970. Terwujudnya budaya keselamatan dan kesehatan kerja merupakan perwujudan dari peningkatan produktifitas kerja dan meminimailisir terjadinya penyakit dan kecelakaan kerja. Salah satu penyebab kecelakaan kerja adalah kelelahan kerja. Lelah dapat merupakan rasa subjektif atau perasaan, kelelahan bisa menimbulkan kecelakaan kerja yang dapat menjadi kronis akibat kelelahan sehari-hari yang tidak/belum pulih. Gejala kelelahan kronis ialah rasa lelah tidak hanya setelah bekerja, tetapi juga sebelum bekerja (Salami, 2016). Kecelakaan kerja dapat disebabkan oleh faktor manusia itu sendiri pada saat bekerja contohnya pada pengemudi. Kelelahan yang terjadi pada pengemudi seperti bekerja dengan waktu kerja lebih dari 8 jam untuk sampai ketujuan dengan jadwal istirahat yang kurang. Waktu tempuh yang cukup lama dan bekerja secara monoton membuat pengemudi mengalami kelelahan sehingga dapat mengganggu konsentrasi dan membuat tingginya resiko kecelakaan (Carlos, 2016).

Kelelahan adalah proses menurunnya efisiensi pelaksanaan kerja dan berkurangnya kekuatan atau ketahanan fisik tubuh manusia untuk melanjutkan kegiatan yang harus dilakukan. Kelelahan didefinisikan sebagai suatu pola yang timbul pada suatu keadaan yang secara umum terjadi pada setiap individu yang tidak sanggup lagi untuk melakukan aktivitasnya. Ada beberapa macam kelelahan yang diakibatkan oleh beberapa faktor, seperti munculnya gejala kesakitan ketika otot menerima beban berlebih (lelah otot), tegang pada mata yang terkonsentrasi pada suatu objek secara terus-menerus (lelah visual), kelelahan saat berfikir (lelah mental) dan lingkungan kerja yang menjemukan (lelah monotonis) (Soedirman, 2014). Faktor resiko kelelahan kerja adalah shift kerja, istirahat kerja yang kurang dan lingkungan kerja yang berbahaya terhadap kesehatan pekerjanya. Shift kerja adalah semua pengaturan jam kerja, baik sebagai pengganti atau sebagai tambahan bekerja pada pagi dan siang hari (Maurits 2010). Kelelahan yang berhubungan dengan jam kerja yang lama, shift kerja malam, dan rotasi kerja menimbulkan akibat negatif pada keselamatan kerja (Lerman, 2012).

Masa kerja dapat menggambarkan pengalaman seseorang dalam menguasai bidang tugasnya, seperti hasil penelitian tentang faktor internal dan eksternal terhadap kelelahan pada pengemudi didapati tidak ada hubungan signifikan antara masa kerja terhadap kelelahan kerja (Darmawan, 2011). Pada umumnya pekerja yang pengalaman kerjanya banyak tidak memerlukan bimbingan dibandingkan dengan pekerja yang pengalamannya sedikit. Semakin lama seseorang bekerja maka akan semakin berpengalaman orang tersebut sehingga kecakapan kerjanya semakin baik, dan mampu untuk mengetahui faktor-faktor yang bisa menyebabkan kelelahan (JME, 2016). Hasil studi pendahuluan di PT. Bukit Makmur yang memiliki sekitar 244 karyawan dibagian operator/pengemudi truk HD (Heavy Duty) dan 91 unit truk HD. Untuk mendukung kegiatan ini armada/kendaraan yang digunakan adalah truk HD agar dapat mengangkut batubara dalam jumlah besar. Tanggung jawab pengangkutan batubara dari area pit (tambang) ke room (hasil penambangan) cukup jauh. PT. Bukit Makmur memulai pekerjaan pada pukul 7:00-18:00 WITA di shift pertama dan di shift kedua pada pukul 18:00-7:00 WITA. Pengemudi dalam keadaan normal biasanya memiliki durasi mengemudi 11 jam dengan waktu istirahat 1 jam. Setelah sampai di room pengemudi membongkar muatan batubara sampai bak truk kosong kemudian kembali lagi ke pit sampai jam waktu istirahat tiba dan beristirahat di base camp PT. Bukit Makmur. Dilihat dari cara bekerja demikian biasanya perasaan lelah terjadi pada akhir jam kerja yaitu ditandai dengan gejala mengantuk dan ada kemungkinan terjadinya kecelakaan lalu lintas (road accident) di tambang batubara. Berdasarkan latarbelakang tersebut maka tujuan penelitian ini adalah untuk mengetahui hubungan antara shift kerja dan masa kerja 
dengan kelelahan kerja pada pengemudi angkutan batubara di PT. Bukit Makmur.

\section{METODE}

Desain penelitian ini menggunakan pendekatan kuantitatif dengan rancangan penelitian cross sectional. Penelitian ini dilakukan pada pengemudi angkutan batu bara di PT. Bukit Makmur. Sampel penelitian ini adalah pengemudi angkutan batubara di PT. Bukit Makmur berjumlah 71 pengemudi. Teknik pengambilan sampel menggunakan metode simple random sampling.

Varibel bebas dalam penelitian ini adalah shift kerja dan masa kerja. Shift kerja adalah pola waktu kerja yang diberikan pada tenaga kerja untuk mengerjakan sesuatu oleh perusahaan. Sedangkan masa kerja adalah waktu kerja yang terhitung mulai dari pertama kali masuk kerja hingga dilakukannya penelitian. Variabel terikat pada penelitian ini adalah kelelahan kerja. Kelelahan kerja adalah menurunnya kapasitas kerja dan ketahanan kerja yang disebabkan oleh beban kerja yang dialami pekerja. Pengukuran kelelahan dengan alat Reaction Timer pada pekerja saat selesai bekerja. Analisis data digunakan dengan cara univariat dan bivariat. Analisis univariat digunakan unuk menghitung distribusi frekuensi. Analisis bivariat adalah analisis yang digunakan untuk mengetahui hubungan shift kerja dan masa kerja dengan kelelahan kerja menggunakan uji Mann-Whitney.

\section{HASIL DAN PEMBAHASAN}

Responden penelitian adalah pengemudi angkutan batu bara di PT. Bukit Makmur yang berlokasi di Kalimantan selatan sebanyak 71 orang. Karakteristik responden dapat dilihat pada tabel 1.

Tabel 1. Distribusi karakteristik responden pengemudi angkutan batu bara di PT Bukit Makmur

\begin{tabular}{llll}
\hline Variabel & Kategori & Jumlah & Persentase \\
\hline \multirow{2}{*}{ Umur } & 18-35 & 42 & 59.2 \\
& 36-55 & 29 & 40.8 \\
Masa & <6 Tahun & 13 & 18.3 \\
kerja & 6-10 Tahun & 33 & 46.5 \\
& >10 Tahun & 25 & 35.2 \\
& Normal & 7 & 9.9 \\
Kelelahan & Ringan & 35 & 49.3 \\
kerja & Sedang & 29 & 40.8 \\
& Berat & 0 & 0 \\
Jenis & Laki-laki & 71 & 100 \\
Kelamin & Perempuan & 0 & 0 \\
Total & & 71 & 100 \\
\hline
\end{tabular}

Analisis bivariat antara shift kerja, masa kerja terhadap kelelahan kerja dapat dilihat pada tabel 2.

Berdasarkan tabel 2 diketahui bahwa hasil analisis menggunakan uji man-whitney didapatkan nilai $\mathrm{p}$ untuk shift kerja terhadap

Tabel 2. Hasil analisis shift kerja terhadap kelelahan kerja pengemudi angkutan batu bara di PT Bukit Makmur Kalimantan Selatan

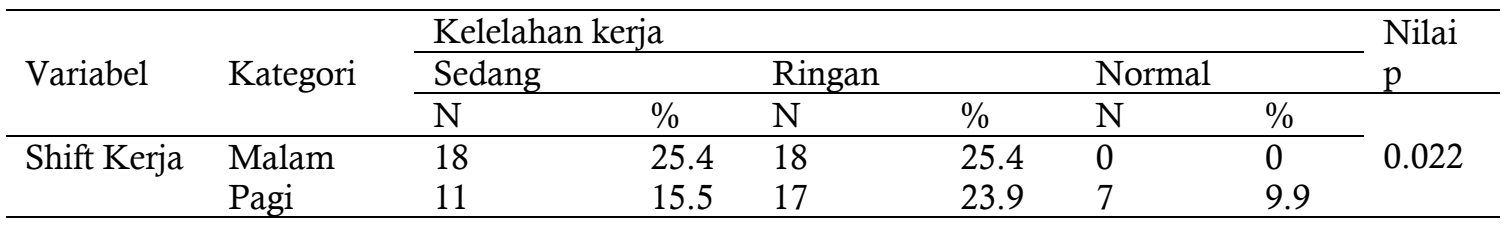

Tabel 3. Hasil analisis masa kerja terhadap kelelahan kerja pengemudi angkutan batu bara di PT Bukit Makmur Kalimantan Selatan

\begin{tabular}{|c|c|c|c|c|c|c|c|c|}
\hline \multirow{3}{*}{ Variabel } & \multirow{3}{*}{ Kategori } & \multicolumn{6}{|c|}{ Kelelahan kerja } & \multirow{2}{*}{$\begin{array}{l}\text { Nilai } \\
\mathrm{p}\end{array}$} \\
\hline & & \multicolumn{2}{|c|}{ Sedang } & \multicolumn{2}{|l|}{ Ringan } & \multicolumn{2}{|c|}{ Normal } & \\
\hline & & $\mathrm{N}$ & $\%$ & $\mathrm{~N}$ & $\%$ & $\mathrm{~N}$ & $\%$ & \\
\hline Masa & Lama & 22 & 31.1 & 3 & 4.2 & 0 & 0 & 0 \\
\hline Kerja & $\begin{array}{l}\text { Baru dan } \\
\text { Sedang }\end{array}$ & 7 & 9.9 & 32 & 45.1 & 7 & 9.9 & 0.000 \\
\hline
\end{tabular}


kelelahan adalah $0.022<$ dari 0.05 sehingga dapat dinyatakan signifikan atau ada hubungan antara shift kerja terhadap kelelahan kerja dengan beban shift malah lebih banyak yang mengalami kelelahan sedangng maupun ringan. Pada tabel 3 diketahui bahwa hasil analisis uji statistic menggunakan uji man-whitney didapatkan nlai $\mathrm{p}$ adalah $0.00<0.05$ sehingga dapat dikatakan bahwa terdapat hubungan yang signifikan antara masa kerja terhadap kelelahan kerja dengan masa kerja yang lama lebih besar mengalami kelelahan kerja sedang dari pada masa kerja baru yang lebih banyak mengalami kelelahan kerja ringan bahkan normal atau tidak mengalami kelelahan kerja.

Penelitian ini dilakukan di PT.Bukit Makmur berada di area lahan pertambangan batu bara milik PT.Adaro Indonesia di jalan Hauling Road Kilometer 70, Kecamatan Tanta, Kabupaten Tabalong, Provinsi Kalimantan Selatan atau sekitar 9 kilometer dari kota Tanjung menuju ke arah Banjarmasin. Pengemudi angkutan batubara di PT. Bukit Makmur Kalimantan Selatan sebagian besar adalah berumur 18-35 tahun berjumlah 42 orang (59.2\%), hal ini menunjukan bahwa tenaga kerja pada unit operator HD masih berusia muda dan produktif. Hasil penelitian ini menunjukan bahwa jenis kelamin pada penelitian yang dilakukan pada pengemudi angkutan batubara di PT.Bukit Makmur Kalimantan Selatan semuanya berjenis kelamin laki - laki sebanyak 71 orang (100\%). Hal ini sesuai dengan ketentuan perusahaan bahwa operator $\mathrm{HD}$ hanya berjenis kelamin laki - laki. Hal ini dikarenakan oleh pekerjaan yang berat dan membutuhkan kekuatan fisik yang baik.

Jenis pekerjaan tertentu harus mempertimbangkan jenis kelamin, seperti pekerjaan yang membutuhkan kegiatan fisik baik langsung atau tidak langsung (lingkungan). Kekuatan seseorang dipengaruhi oleh otot yang menyangkut pada banyaknya serat dan kekuatan pada saat awal kontraksi (relaks). Kekuatan fisik wanita $2 / 3$ dari kekuatan otot laki - laki, akan tetapi dalam hal ketelitian dan ketahanan bekerja pada tempat yang dingin wanita lebih kuat dibandingkan laki - laki. Jenis kelamin dalam pemilihan jenis dan bentuk pekerjaan bukanlah suatu diskriminasi, melainkan untuk memberikan keseimbangan yang harmonis bagi para pekerja dalam memelihara kesejahteraan (Kuswana, 2017).

Hasil penelitian menunjukkan responden yang bekerja pada shift malam dan mengalami kelelahan sedang berjumlah 18 orang (25.4\%). Hasil uji Mann-Whitney didapatkan nilai $p$ sebesar $0.022 \quad(p<0,05)$ yang berarti ada hubungan shift kerja dengan kelelahan kerja pada pengemudi angkutan batu bara. Pada penelitian ini di temukan sebagian besar pengemudi yang mengalami kelelahan adalah pengemudi yang bekerja pada shift malam. Karena kondisi tubuh saat bekerja pada shift malam berbeda dengan shift pagi. Hal ini disebabkan karena pola siklus hidup manusia pada malam hari umumnya digunakan untuk istirahat. Namun karena pengemudi bekerja pada shift malam maka tubuh dipaksa untuk mengikutinya. Hal ini cenderung mengakibatkan terjadinya kelelahan kerja. Akibatnya, pekerja akan mengalami kelelahan pada shift malam yang ditimbulkan disamping itu dipengaruhi oleh faktor lain yang menimbulkan kelelahan pada pengemudi seperti durasi kerja 11 jam dan kekurangan tidur pada malam hari (Yani, 2014).

Shift kerja berpengaruh terhadap keselamatan dan kesehatan kerja. Hal ini berhubungan dengan irama sirkadian (Circadian Rhythm) bekerja pada malam hari menimbulkan kondisi produktivitas kerja lebih rendah di bandingkan dengan produktivitas kerja pada siang hari. Circadian Rhythm adalah semua fisiologis dan psikologis manusia digambarkan sebagai sebuah irama selama periode waktu 24 jam dan menunjukkan adanya fluktuasi harian (Maurits, 2010). Hal ini sejalan dengan penelitian yang memaparkan bahwa pada shift malam pekerja akan mengalami kelelahan cukup besar. Hal ini dikarenakan selain jam kerja lebih dari 8 jam juga diakibatkan oleh kebiasaan tubuh (ritme tubuh) yang seharusnya beristirahat pada malam hari, 
tetapi dijadikan bekerja. Pada kondisi ini akan menimbulkan stress fisik yang diakibatkan kekurangan tidur malam hari, sehingga dapat menambah faktor kelelahan dan menurunkan produktivitas pekerja shift malam (JME, 2016).

Hasil penelitian menunjukkan responden yang mempunyai masa kerja lama dan mengalami kelelahan sedang berjumlah 22 orang (31.0\%). Hasil uji Mann-Whitney didapatkan nilai $p$ sebesar $0.000(p<0,05)$ yang berarti bahwa ada hubungan masa kerja dengan kelelahan kerja pada pengemudi angkutan batu bara. Hal ini disebabkan karena pengalaman kerja seseorang akan mempengaruhi terjadinya kelelahan kerja. Semakin lama seseorang bekerja dalam suatu perusahaan, maka akan mempengaruhi tingkat kelelahan yang di alaminya. Hasil penelitian ini sejalan dengan penelitian mengenai faktor-faktor yang berhubungan dengan kelelahan kerja pada tenaga kerja bongkar muat di pelabuhan tanjung emas semarang yang hasilnya menunjukkan ada hubungan antara masa kerja dengan kelelahan kerja pada tenaga kerja bongkar muat di pelabuhan tanjung emas semarang(Medianto, 2017). Masa kerja lama dan dilakukan secara kontinyu dapat menyebabkan dampak negatif berupa adanya batas ketahanan tubuh terhadap proses kerja yang mengakibatkan timbulnya kelelahan. Penelitian ini berbeda dengan penelitian lain yang menyatakan bahwa yang paling banyak mengalami kelelahan ringan, sedang dan berat adalah pekerja yang masa kerjanya baru atau $<6$ tahun, jadi tidak selamanya masa kerja yang lebih lama lebih banyak menyebabkan kelelahan(JME, 2016).

Pada umumnya pekerja yang pengalaman kerjanya banyak tidak memerlukan bimbingan dibandingkan dengan pekerja yang pengalamannya sedikit. Semakin lama seseorang bekerja maka akan semakin berpengalaman orang tersebut sehingga kecakapan kerjanya semakin baik dan mampu mengetahui faktor-faktor yang bisa menyebabkan kelelahan(Ranupendoyo, 2005) Masa kerja sangat erat kaitannya dengan kemampuan adaptasi antara seorang pekerja dengan lingkungan kerja dan pekerjaannya.
Proses adaptasi dapat memberikan efek positif yaitu dapat menurunkan ketegangan dan performa kerja, sedangkan efek negatifnya adalah batas ketahanan tubuh yang berlebihan akibat tekanan yang didapatkan pada proses bekerja. Hal itu yang menyebabkan timbulnya kelelahan yang membawa pada penurunan fungsi psikologi dan fisiologi. Tekanan fisik pada waktu tertentu akan mengakibatkan menurunnya kinerja otot, gejala yang ditunjukkan dapat berupa melambatnya gerakan, hal ini tidak hanya disebabkan karena beban kerja yang berat namun lebih kepada tekanan yang terakumulasi setiap harinya pada suatu masa yang panjang (Atiqoh, 2014).

\section{PENUTUP}

Terdapat hubungan signifikan antara shift kerja dengan kelelahan kerja pada pengemudi angkutan batu bara di PT. Bukit Makmur Kalimantan Selatan dengan nilai $\mathrm{p}=0.022$. Sedangkan untuk masa kerja juga memiliki hubungan signifikan dengan kelelahan kerja pada pengemudi angkutan batu bara di PT.Bukit Makmur Kalimantan Selatan dengan nilai $p=0.000$. Sehingga untuk meminimalisir dampak negative dari kelelahan kerja maka harus diperhatikan lebih lanjut terhadap pekerja yang memiliki masa kerja yang lama dan shift kerja malam agar adanya upaya peningkatan performa kerja dengan memperhatikan pada waktu kerja dan asupan makanan gizi yang lebih baik dari pada pekerja dengan masa kerja yang baru dan pada pekerja dengan shift kerja pagi.

\section{DAFTAR PUSTAKA}

Atiqoh, J., Wahyuni, I., Lestantyo, D. 2014. FaktorFaktor Yang Berhubungan Dengan Kelelahan Kerja Pada Pekerja Konveksi Bagian Penjahitan di CV. Aneka Garment Gunungpati Semarang. J Kesehat Masy Univ Diponegoro, 2(2):119-26.

Carlos, D., Yasnani, Y., Afa, JR. 2016. Faktor Faktor yang Berhubungan dengan Kelelahan Pengemudi Truk Tangki di Terminal Bbm PT. Pertamina (Persero) Kec. Latambaga Kab. 
H, Akhmad, M., Sukismanto., Hesti, Y., Ariyanto, N. / Shift Kerja dan / JPPKMI 1 (1) (2020)

Kolaka Tahun 2016. J Ilm Mhs Kesehat Masy Unsyiah, 1(4).

Darmawan, S. 2011. Hubungan Faktor Internal Dan Eksternal Terhadap Kelelahan (Fatigue) Pada Pengemudi Bus Antar Kota Trayek SemarangJepara Di Terminal Terboyo Semarang. Universitas Diponegoro.

JME., Kawatu, PAT., Kandou, GD. 2016. Hubungan Antara Umur, Lama Kerja, Dan Getaran Dengan Keluhan Muskuloskeletal Pada Supir Bus Bus Trayek Bitung-Manado Di Terminal Tangkoko Bitung Tahun 2016. Pharmacon, 5(1):297-302.

Kuswana, WS. 2017. Ergonomi dan K3. 3rd ed. Bandung: PT Remaja Rosdakarya.

Lerman, SE., Eskin, E., Flower, DJ., George, EC., Gerson, B., Hartenbaum, N., et al. 2012. Fatigue risk management in the workplace. $J$ Occup Environ Med, 54(2):231-58.

Maurits, LSK. 2010, Selintas tentang Kelelahan Kerja. Yogyakarta: Amara Books.
Medianto, D. 2017. Faktor - Faktor yang Berhubungan dengan Kelelahan Kerja pada Tenaga Kerja Bongkar Muat (TKBM) di Pelabuhan Tanjung Emas Semarang (Studi Pada Pekerja TKBM Bagian Unit Pengantongan Pupuk). Universitas Muhammadiyah Semarang.

Ranupendoyo, S. 2005. Manajemen Personalia. Edisi 4. Yogyakarta: Pustaka Binawan Persindo FE UGM.

Salami, SI Rachmatiah. 2016. Kesehatan Dan Keselamatan lingkungan Kerja. Yogyakarta: Gadjah Mada University Press.

Soedirman,. Suma'mur. 2014. Kesehatan Kerja dalam Perspektif Hiperkes \& Keselamatan Kerja. Jakarta: Erlangga; $224 \mathrm{p}$.

Yani, F., Soleha, TU., Larasati, T., JM. 2014. Hubungan Shift Kerja Malam dengan Kejadian Depresi, Kecemasan dan Stres pada Pekerja di Bagian Maintenance Mesin Penggiling Tebu (Cane Roll Mill) PTPN VII Bunga Mayang. J Major, 3(6):74-83. 